\section{Some Reasons that Mental Health Treatments Are Not Technologies: Toward Treatment Development and Adaptation Outside Labs}

Michael A. Southam-Gerow, Virginia Commonwealth University

This paper discusses positive and negative aspects of the use of the technology metaphor as applied to mental health treatment development and adaptation. The author highlights that treatments to date have been developed almost exclusively for client symptom patterns, though much evidence and theory suggests that other factors, such as nonsymptom client variables and provider and agency variables, may be important to consider as well. In addition, the importance of developing and adapting treatments outside of the lab is emphasized. [Clin Psychol Sci Prac 11: 186-189, 2004]

$\mathbf{P}$ epper's (1942) contribution to modern science's metaphysics was important. By identifying core metaphors that guide theory and research, he focused scientists on the strengths and limitations of the metaphor of choice. Gotham (2004, this issue) makes a great contribution in identifying the importance of conceptualizing the work that an emerging group of researchers are engaged in, namely the diffusion of evidence-based treatment interventions. In particular, she reminds us that moving from the lab to the "real world" will be complex and will likely involve multiple steps. This endeavor will involve research that is focused not only on the effectiveness of treatment programs, but also on the mechanisms that lead to effective diffusion and those that impede diffusion. As one of the researchers engaged in this challenging and rewarding work, I applaud Gotham's contribution. However, her use of technology as the primary metaphor throughout the paper has some unfortunate consequences that should be

Address correspondence to Michael A. Southam-Gerow, Virginia Commonwealth University, Department of Psychology, 808 W. Franklin St. Box 842018, Richmond, VA 23284 2018. E-mail: masouthamger@vcu.edu. considered carefully before we jump onto this metaphorical bandwagon.

Using the metaphor of technology has benefits of which Gotham takes advantage. An important one is that technology developers have long been in the "business" of determining how best to deploy or diffuse their products to the market. Thus, the metaphor has a history of profitable application to the type of endeavor we are undertaking. In addition, federal policymakers are adopting the technology language. This is in part because much of the work done through the Public Health Service results in a "true" technology (e.g., cancer diagnostic tests, dental therapeutics). Even the dictionary definition of technology demonstrates promise for the use of the metaphor: the root words for technology are from the Greek technologia meaning "systematic treatment of an art" (Merriam-Webster, 2003). Indeed, there are many positive aspects to the metaphor and there is no doubt that we can apply some of these to our work quite beneficially. I will not review these positive aspects, though, as there are some negative consequences of using the metaphor.

First and foremost, mental health and substance abuse treatments have important differences from typical technologies such as a new dental therapeutic or a cell phone. One of these differences is that most technologies are "done" once they have been engineered and tested in the lab. In other words, the technology has largely been perfected and then the task is to market that technology. Researchers and policy advocates are not convinced that mental health treatment leaves the lab "perfect" and ready for simple distribution after some marketing efforts (e.g., Strosahl, Hayes, Bergan, \& Romano, 1998; Weisz, Catron, \& Harris, 2000). And the data to date supports their suspicion (e.g., Weiss et al., 2000).

Of course, technology development is usually an iterative process - even simple technologies are not perfected and marketed in one "try." Anyone who has used a personal computer knows that "bugs" exist in the most "perfect" computer software programs and that there is always a new version around the corner. The technology metaphor implies that developers must regularly "re-tool" to correct problems and to add "feature improvements" (i.e., a new functionality). All of this has good application in mental health treatment. However, the technology metaphor has problems 
because it assumes that labs are the place to re-tool treatments. It is not at all clear from our literature if this is true. In fact, some have proposed that we cannot develop treatments in labs that will translate effectively to some (many?) mental health settings (e.g., Chorpita et al., 2002; Hoagwood, Burns, \& Weisz, 2002; Schoenwald \& Hoagwood, 2001; Street, Niederehe, \& Lebowitz, 2000). There is another route that some have advocated, one that would not rely on the technology metaphor. The basic notion is that a good portion of treatment development and adaptation should occur in the settings to which we wish them disseminated (Hoagwood et al., 2002; Weisz, 2000).

An important aspect of this solution is to consider the implications of a range of variables, including (a) client/ family, (b) provider, (c) agency, and (d) system-level variables (e.g., Schoenwald \& Hoagwood, 2001). At first blush, the idea seems apparent. But when treatments are developed, it is rare for treatment developers to go beyond a client-variable focus, and even that is done narrowly, with a near-exclusive focus on symptoms. In other words, as a treatment developer, I develop a treatment for children with disorder X. I do this carefully, drawing on my extensive knowledge of the basic and clinical literatures. I then test the treatment with a sample of youth with disorder X.

The problem with such an approach is twofold. First, it ignores other potentially relevant variables at the client level. For example, to protect internal validity, comorbidity was once a typical exclusion criterion in clinical trials research. More recent clinical trials have begun to include comorbid cases (e.g., Kendall, Brady, \& Verduin, 2001; Weiss, Harris, Catron, \& Han, 2003). Still, though, some evidence indicates that those comorbid cases appear to be different from those seen in typical service clinics (e.g., Southam-Gerow, Weisz, \& Kendall, 2003; Taylor, Francis, Chorpita, Southam-Gerow, \& Lam, 2003). Abundant evidence suggests that comorbidity is common in childhood clinical samples (e.g., National Advisory Mental Health Council [NAMHC] Workgroup, 2001) so an approach to treatment development that does not include more heterogeneous clients does not help us understand what to do for many of the "typical" clinicreferred youth. In addition, there are potentially relevant client-level variables that are not accounted for. As an example, client preference (i.e., which treatment do you want to have?) is rarely considered in treatment development or adaptation. Yet there exists a growing literature on patient decision-making aids that could be adapted to work for mental health treatments (e.g., Rothert et al., 1997).

Further, the client (and symptom) focus of treatment development largely ignores how provider, agency, and service system variables may impact treatment outcome. At the provider level, we know from surveys that many clinicians find manualized treatments unattractive (e.g., Addis \& Krasnow, 2000). One approach would be to obtain feedback from these consumers of mental health treatment and then re-tool based on that input. After all, clinicians are specialized "consumers" of mental health treatments and there is great potential benefit from viewing them as co-engineers/developers rather than as an "end-user" who may not use the "technology" correctly. It seems rather arrogant to assume that we treatment developers have cornered the market on good ideas for treating mental health problems. We do have a specialized set of skills that can contribute to solving the problem, but we are far from having sole access to the solutions. Involving providers in treatment adaptation efforts may lead to better treatment. At the least, the notion is testable. Preliminary effort in this direction has begun (e.g., Kendall, Chu, Gifford, Hayes, \& Nauta, 1998), but more rigorous work is needed to understand how provider characteristics should be considered in treatment adaptation.

Agency and systemic factors, too, have an impact on a treatment, though these factors are rarely considered in the development and adaptation of mental health intervention. Most treatments are developed in a specialty clinic environment whose mission is clinical research. Most mental health consumers receive services in agencies whose mission is service provision and who must deal with daily financial issues that are foreign to grant-supported clinical researchers. Little empirical research addresses the question of whether this makes a difference, though there is a considerable body of research on the importance of organization culture and climate for mental health services outcomes (Glisson \& Hemmelgarn, 1998; Glisson, 2002; Hohmann \& Shear, 2002; Schoenwald \& Hoagwood, 2001). Finally, the amount of supervision and training allotted for providers may differ by agency philosophy and this may be 
relevant in our unfolding work (e.g., Kendall \& Southam-Gerow, 1995). Consideration of these broader variables in treatment development and adaptation may prove a fruitful way to increase the use of evidencebased treatments in a variety of settings.

There is a final problem with the technology metaphor that underscores an area of particular weakness in our evidence base. With most technologies, developers are working toward a particular specification (e.g., adhesion of an implant to a prosthesis); the end goal is, generally speaking, unrelated to human interaction. The iterative process involves adapting the technology so that user "error" is minimized and the technology can operate as designed. However, most mental health treatments are specifically designed to occur in interpersonal relationships. As such, user "error" becomes more difficult to define, in part because we do not know what the critical variables are in effecting change (e.g., Kazdin, 2003). Indeed, although the importance of the therapeutic relationship has long been argued in the literature, many have concluded that it is one of the key ingredients of successful treatment (e.g., Beutler \& Harwood, 2002; Lambert \& Barley, 2001; Shirk \& Karver, 2003). Yet our "technology" development has tended to emphasize techniques and outcome rather than relationships and processes. It is not clear if such an emphasis is warranted, but adoption of the technology metaphor wholesale would retain this focus.

In sum, we should remember Pepper and remain aware of the strengths and limitations of the metaphor(s) we live and work by. Technology as a metaphor has and will continue to lead to progress. But there are some ways in which the metaphor will hamper our efforts.

As a final note, I want to point out that by promoting more research outside of the lab, I am not suggesting that we abandon lab work. The benefits of lab-based treatment development and testing are plentiful and we remain a young science. Thus, lab-based work continues to be a critical part of our agenda. However, the nature of our "technology" is that it cannot be perfected in our labs. Thus, out of the labs some of us must go.

\section{ACKNOWLEDGMENT}

I want to acknowledge Alyssa M. Hershberger for her careful reading and thoughtful comments on an earlier version of this paper.

\section{REFERENCES}

Addis, M. E., \& Krasnow, A. D. (2000). A national survey of practicing psychologists' attitudes toward psychotherapy treatment manuals. Journal of Consulting \& Clinical Psychology, 68, 331-339.

Beutler, L. E. \& Harwood, T. M. (2002). What is and can be attributed to the therapeutic relationship? Journal of Contemporary Psychotherapy, 32, 25-33.

Chorpita, B. F., Yim, L. M., Donkervoet, J. C., Arensdorf, A., Amundsen, M. J., McGee, C., et al. (2002). Toward largescale implementation of empirically supported treatments for children: A review and observations by the Hawaii Empirical Basis to Services Task Force. Clinical Psychology: Science \& Practice, 9, 165-190.

Glisson, C. (2002). The organizational context of children's mental health services. Clinical Child \& Family Psychology Review, 5, 233-253.

Glisson, C. \& Hemmelgarn, A. (1998). The effects of organizational climate and interorganizational coordination on the quality and outcomes of children's service systems. Child Abuse \& Neglect, 22, 401-421.

Gotham, H. J. (2004). Diffusion of mental health and substance abuse treatments: Development, dissemination, and implementation. Clinical Psychology: Science and Practice, 11, 160-176.

Hoagwood, K., Burns, B. J., \& Weisz, J. R. (2002). A profitable conjunction: From science to service in children's mental health. In B. J. Burns \& K. Hoagwood (Eds.), Community treatment for youth: Evidence-based interventions for severe emotional and behavioral disorders (pp. 327-338). New York: Oxford University Press.

Hohmann, A. A., \& Shear, M. K. (2002). Community-based intervention research: Coping with the "noise" of real life in study design. American Journal of Psychiatry, 159, 201-207.

Kazdin, A. E. (2003). Psychotherapy for children and adolescents. Annual Review of Psychology, 54, 253-276.

Kendall, P. C., Brady, E. U., \& Verduin, T. L. (2001). Comorbidity in childhood anxiety disorders and treatment outcome. Journal of the American Academy of Child $\mathcal{E}$ Adolescent Psychiatry, 40, 787-794.

Kendall, P. C., Chu, B. Gifford, A., Hayes, C., \& Nauta, M. (1998). Breathing life into a manual. Cognitive and Behavioral Practice, 5, 177-198.

Kendall, P. C., \& Southam-Gerow, M. A. (1995). Issues in the transportability of treatment: The case of anxiety disorders in youth. Journal of Consulting and Clinical Psychology, 63, 702-708.

Lambert, M. J. \& Barley, D. E. (2001). Research summary on the therapeutic relationship and psychotherapy outcome. 
Psychotherapy: Theory, Research, Practice, Training, 38, 357-361.

Merriam-Webster. (2003). Merriam-Webster's Collegiate Dictionary (11th Edition). Springfield, MA: Author.

National Advisory Mental Health Council Workgroup on Child and Adolescent Mental Health Intervention Development and Deployment. (2001). Blueprint for change: Research on child and adolescent mental health. Washington, D.C.: Author.

Pepper, S. C. (1942). World hypotheses. Berkeley, CA: University of California Press.

Rothert, M. L., Holmes-Rovner, M., Rovner, D., Kroll, J., Breer, L., Talarczyk, G., et al. (1997). An educational intervention as decision support for menopausal women. Research in Nursing \& Health, 20, 377-387.

Schoenwald, S. K., \& Hoagwood, K. (2001). Effectiveness and dissemination research: Their mutual roles in improving mental health services for children and adolescents. Emotional \& Behavioral Disorders in Youth, 2,3-4, 18-20.

Shirk, S. R. \& Karver, M. (2003). Prediction of treatment outcome from relationship variables in child and adolescent therapy: A meta-analytic review. Journal of Consulting $\mathcal{E}$ Clinical Psychology, 71, 452-464.

Southam-Gerow, M. A., Weisz, J. R., \& Kendall, P. C. (2003). Childhood anxiety disorders in research and service clinics: Preliminary examination of differences and similarities. Journal of Clinical Child and Adolescent Psychology, 32, 375-385.
Street, L. L., Niederehe, G., \& Lebowitz, B. (2000). Toward greater public health relevance for psychotherapeutic intervention research: An NIMH workshop report. Clinical Psychology: Science and Practice, 7, 127-137.

Strosahl, K. D., Hayes, S. C., Bergan, J., \& Romano, P. (1998). Assessing the field effectiveness of Acceptance and Commitment Therapy: An example of the manipulated training research method. Behavior Therapy, 29, 35-64

Taylor, A. A., Francis, S. E., Chorpita, B. F., Southam-Gerow, M. A., \& Lam, C. (2003, November). Examining differences between publicly and privately referred youth at a university-based clinic. Poster session presented at the Association for the Advancement of Behavior Therapy Convention, Boston, MA.

Weiss, B., Catron, T., \& Harris, V. (2000). A 2-year follow-up of the effectiveness of traditional child psychotherapy. Journal of Consulting and Clinical Psychology, 68, 1094-1101.

Weiss, B., Harris, V., Catron, T., \& Han, S. S. (2003). Efficacy of the RECAP intervention program for children with concurrent internalizing and externalizing problems. Journal of Consulting \& Clinical Psychology, 71, 364-374.

Weisz, J. R. (2000). Lab-clinic differences and what we can do about them: I. The Clinic-Based Treatment Development Model. Clinical Child Psychology Newsletter, 15,1-3, 10.

Received November 17, 2003; revised December 16, 2003; accepted December 16, 2003. 